\title{
SÍMBOLOS DE MASCULINIDAD(ES). INVESTIGACIÓN PARA LA CREACIÓN DE UNA PROPUESTA VISUAL SOBRE GÉNERO
}

\author{
Claudio Petit Laurent Charpentier \\ Universidad Complutense de Madrid \\ claudiopetitlaurent@gmail.com
}

\section{RESUMEN}

El presente texto surge como un proceso de investigación artística que tiene como objetivo elaborar una propuesta visual que aborde la problemática de la identidad masculina en el contexto social y cultural actual. Para ello se hace necesario generar un marco teórico acerca de la temática de género, partiendo de las teorías feministas y de los estudios de masculinidad, que permitirán establecer las categorías de análisis de las que surgirá el imaginario para la elaboración de la propuesta visual. Se parte de las nociones del género entendido como construcción social y, por lo tanto, se establece un vínculo de referencia visual con la ciudad como manifestación material de las estructuras de significado que delimitan los procesos de elaboración de identidad de los individuos. Finalmente, sobre la base de una metodología de análisis semiótico respecto del conjunto de signos y símbolos que componen el imaginario construido a partir de las categorías planteadas por el marco teórico, se articulará, a través del lenguaje pictórico, una propuesta visual que plantee un cuestionamiento a la rigidez de dichas estructuras, aludiendo a la diversidad de masculinidades que se viven en la actualidad.

Palabras clave: masculinidades, feminismo, queer, investigación artística, símbolos, construcciones sociales.

\section{SYMBOLS OF MASCULINITY (S). RESEARCH FOR THE CREATION \\ OF A VISUAL PROPOSAL ABOUT GENDER}

\section{Abstract}

The present text emerges as a process of artistic research that aims to elaborate a visual proposal about the problematic of masculine identity in the current social and cultural context. For this, it is necessary to generate a theoretical framework on the subject of gender, starting with the feminist theories and the studies of masculinity, which will allow to establish the categories of analysis from which the imaginary will arise for the elaboration of the visual proposal. It starts from the notions of the gender understood as social construction, and therefore establishes a visual reference link with the city as a material manifestation of the structures of meaning that delimit the processes of elaboration of identity of the individuals. Finally, on the basis of a semiotic analysis methodology regarding the set of signs and symbols that make up the imaginary built from the categories proposed by the theoretical framework, a visual proposal will be articulated through pictorial language that poses a questioning the rigidity of these structures, alluding to the diversity of masculinities that are experienced today.

KEYWORDS: masculinities, feminism, queer, artistic research, symbols, social constructions.

DOI: https://doi.org/10.25145/j.histarte.2021.02.01

Revista de Historia del Arte, 2; diciembre 2021, pp. 11-30; ISSN: e-2660-9142 


\section{INTRODUCCIÓN}

La presente investigación tiene su origen en la reflexión acerca de las construcciones de género que regulan el proceso de elaboración o definición de la identidad de las personas, principalmente en el ámbito urbano. Dicha reflexión busca encontrar un vínculo entre las ideas planteadas por la teoría de género y las vertientes que analizan el concepto de masculinidad/masculinidades, con imágenes que permitan elaborar metáforas visuales respecto a ese proceso de identificación con las representaciones sociales, enfocándose principalmente en los símbolos asociados a los hombres.

Para comenzar es necesario reconocer los principios teóricos respecto a los conceptos de identidad y de género, puesto que será a partir de ello cuando surgirá la reflexión que permitirá la observación analítico-reflexiva que nutrirá el imaginario sobre el cual se establecerán las relaciones de significación para construir metáforas visuales. Lo que se pretende, a través de la visualidad, es construir imágenes que, a partir del contrapunto y la dialéctica visual, generen un quiebre que haga eco de la deconstrucción crítica de las estructuras sociales que determinan el rol de los hombres en la sociedad actual, marcada por un profundo giro en las relaciones de identificación con las representaciones sociales de género.

\section{MARCO TEÓRICO}

Cuando Simone de Beauvoir plantea aquella frase que cimenta las reflexiones y análisis acerca de la feminidad: «No se nace mujer, se llega a serlo» (Beauvoir 2005, p. 371), comienza un cuestionamiento que permitirá carcomer los pilares de una estructura constitutiva de las dinámicas culturales y sociales que ha resistido como ninguna otra los embates de la modernidad. Cuando comenzamos a hablar de género, ponemos sobre la mesa el cuestionamiento acerca de un aspecto fundamental de la identidad del individuo. El concepto de género surge como la forma en que las primeras feministas se refieren a la organización social de las relaciones entre los sexos. De esta manera, el análisis y las políticas del movimiento buscan desprenderse del determinismo biológico que estructura y configura las relaciones sociales de hombres y mujeres a partir de la diferencia anatómica sexual. Como lo plantea Joan Scott: «El género es un elemento constitutivo de las relaciones sociales basadas en las diferencias que distinguen los sexos, y [...] es una forma primaria de relaciones significantes de poder» (1996, p. 23).

En términos históricos, han existido diferentes enfoques en el tratamiento de las problemáticas de género. Scott (1996) las clasifica en relación con sus diferentes posiciones teóricas, partiendo del enfoque puramente feminista, que se orienta hacia la explicación del patriarcado y la situación de opresión de la mujer; el segundo, abordado desde el materialismo marxista, entiende el género en analogía o similitud con las problemáticas de clase y, por lo tanto, establece un vínculo entre las determinaciones sociales que establece el patriarcado y el capitalismo; $y$, finalmente, un tercer enfoque, que es el que corresponde a los estudios basados en el psicoanáli- 
sis, que explican la producción y reproducción de la identidad de género del sujeto y que surgen desde los estudios estructuralistas y posestructuralistas y que se centran en los significados de las relaciones y los objetos.

De esas tres definiciones surge como concepto fundamental la idea de la mujer considerada en su calidad de cuerpo/objeto y que, por lo tanto, es suceptible de ser poseído y controlado. Así mismo, esa relación de poder del hombre sobre la mujer se manifiesta más allá de la genitalidad que determina esa diferencia y se traslada de manera simbólica a los objetos cotidianos como son la vestimenta, los utensilios y herramientas, los que a su vez proyectan las conductas y comportamientos sociales de hombres y mujeres a ciertos contextos.

En este sentido, la perspectiva semiótica que se evidencia en los estudios sociológicos partiendo por el interaccionismo simbólico, hasta el construccionismo social, entenderán que la identidad es un proceso contextualizado y contingente, definiendo por lo tanto el género como una construcción cultural que eleva normas y modelos de actuación social asociados al cuerpo, estableciéndose como una estructura condicionante en la construcción del sí mismo.

Sabemos que la identidad es una operación de doble articulación, tanto de una diferenciación como de una generalización, es decir, de autorreconocimiento de cualidades excluyentes y, al mismo tiempo, de cualidades inclusivas que permiten ser parte de un grupo o colectivo. No obstante, en ese proceso de identificación opera principalmente la percepción a través de lo visual, que permite tomar conciencia en primer término de la diferencia sexual a partir del cuerpo y la genitalidad y que a su vez se extrapola a los elementos culturales que proyectan esas construcciones.

Las visiones más actuales del concepto de género, al concebirlo como una construcción social y no como una esencia, plantean que, debido al carácter asimétrico, jerárquico, rígido y represor, puede y debe ser deconstruido, entendiendo esto como lo planteara Jacques Derrida (1996), es decir, como la inversión y desplazamiento de los binomios que se configuran en oposición jerárquica y que se entienden como naturalizados. Judith Butler, una de las principales teóricas posestructuralistas, en referencia a esa validación del género en su naturalización señala: «El género también es el medio discursivo/cultural a través del cual la "naturaleza sexuada" o "un sexo natural" se forma y establece como "prediscursivo", anterior a la cultura, una superficie políticamente neutral sobre la cual actúa la cultura» (2007, p. 56).

Esa deconstrucción de la estructura jerárquica plantea entonces la posibilidad de establecer procesos retóricos desde lo discursivo, trasladando o desviando las significaciones de los elementos normalmente asociados a cada género a otro contexto de significación o al opuesto, construyendo metáforas y niveles de connotación que funcionan desde el contrapunto y la disrupción.

Judith Butler, desde lo que se puede llamar posfeminismo, dentro del cual se enmarcan las teorías queer, además de otras muchas teóricas feministas, entre ellas Monique Wittig (2006), Gayle Rubin (1975), Luce Irigaray (1977), ha problematizado el género más allá de apuntar a una asimilación de la mujer con el hombre, sino concibiendo que la negatividad de la estructura radica en que se impone un orden jerárquico androcéntrico, y todo lo vinculado a lo femenino es relegado a una posición de inferioridad. Es por ello por lo que, desde esta nueva perspectiva, 
se otorga fundamento teórico al activismo político no solo de mujeres, sino también de gais, lesbianas y personas trans o no binarias, puesto que son personas que no calzan con la estructura normativa que establece conductas determinadas para su género. Así surge un cuestionamiento acerca del proceso de construcción de identidad sobre el que Judith Butler plantea: «Si la "identidad" es un efecto de las prácticas discursivas, ¿hasta qué punto la identidad de género, vista como una relación entre sexo, genero, práctica sexual y deseo, es el efecto de una práctica reguladora que puede definirse como heterosexualidad obligatoria?» (2007, p. 73).

Wittig, desde una posición más radical, no solo plantea que las estructuras binarias deben ser deconstruidas, sino que han de ser destruidas, puesto que las categorías de sexo se extrapolan forzosamente a las relaciones sociales:

Los sexos, a pesar de su diferencia "constitutiva», deben inevitablemente desarrollar relaciones de categoría a categoría. Dado que pertenecen a un orden natural, esas relaciones no pueden ser consideradas como relaciones sociales. Esta concepción que impregna todos los discursos, incluidos los del sentido común [...], es el pensamiento de la dominación (2006, p. 25).

Esa matriz -cuerpo/comportamiento/deseo sexual- que asocia de manera rígida e indivisible las categorías propias de la identidad construye una base que establece como «natural» la relación de dominación de una categoría sexual sobre la otra y, al mismo tiempo, las limita a solo dos. La categoría de sexo ratifica, por lo tanto, una estructura normativa estricta que se extrapola a otras dimensiones de la identidad de manera artificiosa y que determina una heterosexualidad obligatoria sancionando todo lo que no se ajuste a ella (Wittig 2006, p. 26).

A raíz de lo anterior, cabe precisar entonces que, a pesar de que comúnmente se diferencien los conceptos de género y sexo a partir de la relación con la cultura y la naturaleza respectivamente, esto no es tan simple porque, como hemos visto, la sexualidad también está sujeta a procesos de significación asignados a aspectos de orden natural de los cuerpos y es, por lo tanto, una categoría política. A partir de entonces, la mirada se diversifica y se entiende que la estructura cultural de género encasilla y limita a todos los miembros de la sociedad, aunque no a todos de la misma manera. Por ello, Monique Wittig señala categóricamente: «Debemos entender que este conflicto no tiene nada de eterno, y que para superarlo debemos destruir política, filosófica y simbólicamente las categorías de "hombres" y "mujeres"» (2006, p. 15).

Del cuadro (tabla 1), las dimensiones de deseo y comportamiento nos arrojan conceptos que se manifiestan en el cuerpo y en la conducta más allá de la genitalidad, haciendo observable, es decir, visible, una serie de signos que permiten reconocer la estructura binaria heteronormada imperante y la manera de establecer simbolismos que la comunican, reproducen y proyectan en el orden social. La asignación de significados jerárquicos a los órganos sexuales -que establecen la relación de dominación del hombre sobre la mujer en virtud de la percepción de la penetración como acto invasivo y de dominio- es la construcción cultural que sustenta toda una serie de símbolos que comunican visualmente la estructura opresiva sobre lo femenino; la actividad de lo masculino y la pasividad de lo femenino; la fuerza de lo masculino y la fragilidad de lo femenino. 


\begin{tabular}{|c|c|c|c|c|}
\hline \multicolumn{5}{|c|}{ TABLA 1. ESQUEMA DE LA ESTRUCTURA HETERONORMADA } \\
\hline & \multicolumn{2}{|l|}{ НомвRе } & \multicolumn{2}{|l|}{ Mujer } \\
\hline & & Visualidad & & Visualidad \\
\hline Cuerpo & Pene & Convexo & Vagina & Cóncavo \\
\hline Deseo sexual & $\begin{array}{l}\text { Penetrar a una mujer/ } \\
\text { Dar/Poseer }\end{array}$ & $\begin{array}{l}\text { Actividad/ } \\
\text { Acción }\end{array}$ & $\begin{array}{l}\text { Ser penetrada por un hombre/ } \\
\text { Recibir//Ser poseída }\end{array}$ & Pasividad \\
\hline Comportamiento & Dominación/Poder & $\begin{array}{l}\text { Potencia/ } \\
\text { Fuerza }\end{array}$ & Sumisión/Subordinación & $\begin{array}{l}\text { Fragilidad/ } \\
\text { Delicadeza }\end{array}$ \\
\hline
\end{tabular}

Fuente: elaboración propia.

Derivado de lo que hemos expuesto en los párrafos precedentes, a partir de la década de los ańos 80 , las ciencias sociales entienden que el problema de género es un problema del ser humano, no solo de la mujer, y, por lo tanto, lo que se conocía acerca de los hombres era también limitado por las construcciones culturales heteronormadas y androcéntricas, que parecían asumir que todos los hombres se acomodaban a ellas por el privilegio de la posición jerárquica que les tocaba. Autores como Kimmel (1987), Kaufman (1989), Gilmore (1990), Badinter (1993) y Connell (1995), entre otros, desarrollan y orientan sus investigaciones a comprender la masculinidad y su situación respecto a la norma de hegemonía heterosexual cuya persistencia y su crisis tienen y tendrán efectos en la concepción del ser hombre en la sociedad, en la medida en que es una construcción abstracta ante la cual todo ser humano realiza su proceso de identificación. Como señala Kaufman respecto a los roles normativos que regulan el comportamiento de los sujetos:

Sin duda los roles, expectativas e ideas acerca del comportamiento apropiado sí existen, pero la esencia del concepto de género no está en la prescripción de algunos roles y la proscripción de otros; después de todo, la gama de posibilidades es amplia y cambiante y, además, rara vez son adoptados sin conflicto. Al contrario, lo clave del concepto de género radica en que éste describe las verdaderas relaciones de poder entre hombres y mujeres y la interiorización de tales relaciones (1995, p. 4).

Esa estructura binaria heterosexual, la heterosexualidad obligatoria, basada en la genitalidad y la reproducción, definirá entonces que en la cúspide de la sociedad estará un hombre heterosexual y será, por tanto, una sociedad patriarcal, la que se define: «No solo como un sistema de poder de los hombres sobre las mujeres, sino de jerarquías de poder entre distintos grupos de hombres y también entre diferentes masculinidades» (Kaufman 1995, p. 4).

Aun cuando los estudios del feminismo y los estudios acerca de las masculinidades la han cuestionado, la estructura cultural binaria persiste hasta hoy. Lo que han hecho esas teorías es dar validez al conflicto y revelar la fragilidad de la matriz cultural; Butler se refiere a ello diciendo:

En la medida en que la «identidad» se preserva mediante los conceptos estabilizadores de sexo, género y sexualidad, la noción misma de «la persona» se pone en duda por la aparición cultural de esos seres con género «incoherente» $\mathrm{o}$ «discontinuo» que aparen- 
temente son personas, pero que no se corresponden con las normas de género culturalmente inteligibles mediante las cuales se definen las personas (2007, pp. 71 y 72).

La existencia de personas que se escapan de la norma -y la manifestación explícita de la incomodidad y del conflicto que esas personas viven y provocan en la sociedad- revela que la norma no responde a la realidad y que se impone artificiosamente como modelo y patrón de conducta que coacciona, acota y regula el desarrollo de los sujetos en la construcción sí mismos. La norma, por lo tanto, impide a muchos individuos la posibilidad de ser, como lo expresa Butler (2007): «La matriz cultural -mediante la cual se ha hecho inteligible la identidad de género- exige que algunos tipos de "identidades" no puedan "existir": aquellas en las que el género no es consecuencia del sexo y otras en las que las prácticas del deseo no son "consecuencia” ni del sexo ni del género» (2007, p. 72).

La matriz expuesta más arriba plantea unas relaciones encadenadas que, al ser rotas estableciendo relaciones alternativas entre los signos de la corporalidad, del comportamiento, del deseo sexual y todas las manifestaciones del género en el contexto social, articulan un mensaje disruptivo que construye en la desviación del signo una metáfora que cuestiona la estructura, que la pone en entredicho.

Gais, bisexuales y lesbianas, además de transexuales, intersexuales y personas no binarias, no tienen derecho a existir dentro de esa matriz heteronormada. Se establece así una categorización de seres humanos validados y otros que, de no adaptarse, quedan invisibilizados en varios aspectos de la vida social o, por el contrario, su visibilización resulta particularmente interesante desde el punto de vista estético y visual, pues son los recursos de la comunicación visual los que adquieren un carácter discursivo y político, además de estético. Tras el levantamiento de todas las teorías expuestas, se han abierto espacios para la diversidad sexual que cuestionan subversivamente las construcciones de género; sin embargo, es una lucha que aún encuentra resistencia en la normativa jurídica que consolida la estructura binaria y patriarcal (Butler 2007).

Cuando señalamos que en la cúspide de la sociedad está el hombre heterosexual, debemos especificar que en realidad lo que hace la construcción cultural del género es establecer, a partir del discurso, un modelo de actuación que será contextual e histórico, y que se articulará como una referencia que quedará definida siempre por la cualidad de dominación y ante la que hombres y mujeres debemos responder identificándonos como tales, o como opuestos. Oscar Guash define la masculinidad como:

Un concepto sociológico de tipo instrumental que tiene su origen en el feminismo y en el movimiento gay, y que sirve para reflexionar sobre el género en tanto que elemento de estructura social. [...] La masculinidad es un todo que engloba tanto las normas de género como sus desviaciones (2008, p. 33).

Por otra parte, el construccionismo social y cultural entenderá que existe una diversidad de masculinidades, y que aquel modelo es precisado como la masculinidad hegemónica, la que queda definida por una serie de conductas delimitadas 
por una norma consistente en un complejo articulado que establecerá los requisitos necesarios para ser considerado hombre y ostentar así la posición de poder.

Michael Kimmel (1997) señala que «la virilidad no es estática ni atemporal, es histórica; no es la manifestación de una esencia interior, es construida socialmente; no sube a la conciencia desde nuestros componentes biológicos; es creada en la cultura. La virilidad significa cosas diferentes en diferentes épocas para diferentes personas» (p. 49).

Entendiendo la virilidad como el conjunto de atributos propios del varón, corresponderá, entonces, a una serie de características observables que se atribuirán a la masculinidad dominante. A ello se refiere Gilmore (1994) al explicar cómo se concibe la masculinidad: «La verdadera virilidad es diferente de la simple masculinidad anatómica, de que no es una condición natural que se produce espontáneamente por una maduración biológica, sino un estado precario o artificial que los muchachos deben conquistar con mucha dificultad» (p. 22).

Ahora bien, ¿qué es ser hombre? ¿Cuáles son las características visuales que deberá tener la personalidad del varón? Tenemos que situarnos en el contexto cultural para poder establecer un campo de categorías que puedan enmarcar posibles respuestas a estas preguntas. Ese posicionamiento no será sencillo teniendo en cuenta que la modernidad tardía «no solo supone una violenta ruptura con alguna o con todas las condiciones históricas precedentes, sino que se caracteriza por un proceso interminable de rupturas y fragmentaciones internas» (Harvey 1998 , pp. 26 y 27).

No obstante, la diversidad de canales y de formas en las que los discursos y significados culturales circulan-como, por ejemplo, los medios de comunicación de masas, los espacios, la ciudad, las instituciones, etc.- permite que coexistan diferentes construcciones y estructuras de significado y relacionadas entre sí. Podría pensarse que la modernidad amplía el espectro de posibilidades de ser. Sin embargo, lo que hace es relativizar todo y situarnos en un campo de incertidumbre donde esas alternativas son desprovistas de sentido, articulándose en el mercado como arquetipos vacíos.

En términos concretos, en nuestra sociedad occidental, podemos convivir con construcciones estereotipadas acerca de la masculinidad hegemónica que no necesariamente se presentan unitariamente, sino que se fragmentan y se orientan según el contexto específico en que se imponen siempre manteniendo el principio rector del ejercicio del poder y de la posición más alta en la jerarquía social, en lo que a género se refiere.

Ahora bien, esos estereotipos de masculinidad hegemónica ¿cómo surgen? ¿Sobre qué base se articulan esos significados? Como hemos dicho antes, las construcciones de género surgen de la asignación de significados culturales a aspectos propios de la biología y de la naturaleza, es decir, la sexualidad. Desde los estudios de la masculinidad (Kimmel; Connell; Gilmore; Badinter) coinciden en que el carácter relacional del género, que en el caso de la masculinidad presenta un marcado énfasis en la negación, vale decir que el proceso de identificación se articula prioritariamente a partir de la diferenciación respecto a la alteridad, la mujer, lo que implica que «los varones aprenden antes lo que no deben hacer o ser para lograr la masculinidad que lo que deben hacer o ser» (Jociles 2001, p. 3). 
El estereotipo y la negación aportan nuevamente referencias conceptuales que pueden traducirse desde la visualidad. El estereotipo principalmente se manifiesta en las construcciones mediatizadas en la cultura posmoderna de manera profusa y los recursos de la retórica visual permiten evidenciar la negación desde técnicas como el contraste, la exageración, la reticencia, que elaboren figuras retóricas desde la paradoja, la sinécdoque, etc. (Dondis 2017).

La masculinidad modélica será un ideal que se logre en la medida en que se repriman comportamientos y actitudes que se pueden presentar en el desarrollo del niño. De ahí, por ejemplo, es que se insta a que los niños aprendan a no mostrar sus emociones y que no se muestren vulnerables ante los demás. Desde las perspectivas psicoanalíticas, esa negación se hace necesaria para poder construir la identidad propia a partir de la represión del instinto y el rechazo hacia la madre, de la cual es necesario diferenciarse para conseguir la autonomía y que se asocia con el miedo a la castración (Lacan 1958). En el caso de la niña, esa diferenciación no es requerida por la sociedad, pues ella, como su madre, asumirá también esa «función» de maternidad; por lo tanto, su identidad se construirá desde la asimilación (Chodorov 1984).

Gilmore (1994), Herdt (1981, 1988), Brandes (1980) y muchos otros antropólogos, en sus estudios de la masculinidad en diferentes trabajos etnográficos, hacen alusión a los ritos que marcan hitos en la trayectoria vital de los jóvenes en el momento en que se hacen hombres. Ritos que implicarán, según el contexto, experiencias de alejamiento total de la madre, una desvinculación con el espacio de seguridad y, por lo tanto, supondrá la exposición al riesgo, al dolor físico y al peligro. Por lo general, la experiencia que marca la diferencia con la niñez tendrá que ver con la violencia y la agresividad, puesto que se entenderá que esa es la forma de enfrentar lo hasta entonces desconocido y temido. La violencia será la forma de demostrar que se ha superado el miedo a enfrentar de manera autónoma el entorno, que se concibe siempre como hostil.

El rito en sí mismo es una manifestación simbólica y, por lo tanto, tiene en gran medida un carácter artístico que se relaciona con lo performativo y que se articula a partir de signos con fuerza estética. La violencia también cuenta con signos que permiten construir connotaciones vinculadas a la masculinidad cuando los relacionamos con referencias contextuales que aludan a la resistencia o a la fuerza.

La masculinidad hegemónica es el estereotipo que ocupa la posición dominante en el binomio heteronormativo, que también delimita un estereotipo de feminidad subordinada, opuesta y complementaria de aquel modelo de hombre. Si el hombre debe ser fuerte, frío y violento, la mujer debe ser débil, emocional y pacífica, lo que connotará su posición de sometimiento, en el sentido de que esas características la hacen incapaz de desenvolverse de manera autónoma. Esos estereotipos son los que manifiestan, de manera concreta, la norma de comportamiento que modela la identidad de género que se socializa en las producciones culturales, tanto materiales como inmateriales, como, por ejemplo, la familia, el sistema educativo, la ley, los medios de comunicación y la división social del trabajo (Guash 2008).

Dentro del estereotipo, o la construcción modélica del hombre, un aspecto relevante es el carácter público de la masculinidad. Respecto a ello, Gilmore (2008) hace un análisis interesante a partir de sus investigaciones etnográficas. Por una 
parte, la masculinidad debe ser demostrada socialmente ante los pares, por lo tanto, el varón se enfrenta constantemente al ser juzgado y a ser juez respecto al cumplimiento del estándar. Por otra parte, el autor releva el carácter utilitario y pragmático que impone la masculinidad al varón, el deber de ser eficiente en el cumplimiento de funciones que son eminentemente sociales y públicas. En ese sentido, la ciudad funciona como un símbolo de la masculinidad en la medida en que es la concretización de las estructuras sociales. Por otra parte, la mujer, debido a su fragilidad, emocionalidad y candidez, ocupará un lugar interior, en el hogar, protegida por los muros construidos por su hombre, quien se enfrenta a los peligros del mundo exterior, lleno de hombres. Ante ellos el varón debe demostrar su valía: «La eficacia de un hombre se mide cuando los demás le ven en acción y pueden evaluar su actuación» (Gilmore 2008, p. 46). De lo anterior podemos comprender la lógica competitiva que marca los procesos de construcción de identidad, que es exacerbada y potenciada, por ejemplo, en el ámbito deportivo en la adolescencia y que luego se reproduce en el mundo laboral.

La función del varón, en ese escenario público, será entonces demostrar su capacidad. Tendrá que exponer no solo que es bueno, sino que es bueno como hombre, es decir, que es capaz de procrear, proveer y proteger lo suyo de manera eficaz. Todo lo anterior, proyectándose hacia lo exterior, dejando a sus espaldas la introspección, el hogar, lo doméstico, lo íntimo, que es más propio de la mujer (Gilmore 2008).

Habiendo hecho una revisión de los conceptos relativos a las teorías de género y establecidas ciertas relaciones conceptuales que permiten derivar signos y símbolos que son suceptibles de ser utilizados para el desarrollo de una propuesta visual, pasaremos a continuación a recoger las reflexiones y análisis acerca de un proceso creativo que pretende abordar la problemática de la identificación de género, particularmente de una masculinidad que cuestiona la construcción hegemónica y que, comprendida en la misma lógica de Simone de Beauvoir, evidencia que no se nace hombre, se llega a serlo.

\section{ANTECEDENTES HISTÓRICOS}

Todo movimiento social que se sustenta y genera reflexiones y análisis teóricos desde las ciencias sociales tiene un impacto profundo en los artistas que lo viven y por lo tanto en la creación artística, lo que a su vez genera nuevas formas de conocimiento y reflexión. Por ello, el arte fue un lugar en el que la voz del feminismo se abrió espacio en un mundo que hasta la década de los 60 también estaba limitado a los hombres; pero, además, y por lo mismo, mayoritariamente a una visión masculina heteronormativa patriarcal en la creación artística. Como señala Amelia Jones:

Siendo que la objetualización de las imágenes a partir de estructuras heterosexuales binarias de la diferencia sexual ha predominado de forma arraigada en la cultura euroamericana, no sorprende que las feministas se hayan esforzado por recuperar la representación y la experiencia de los cuerpos de las mujeres (2010, p. 46). 
Desde entonces, obras de artistas como Magdalena Abakanowicz en los años 60, Carolee Scheemann en los 70 y 80; Judy Bambler en los 90, entre muchas otras curadoras, o investigadoras como Judy Chicago y Myriam Schapiro, introdujeron el discurso feminista en exposiciones de arte con fuerte impacto en el mundo cultural.

Si bien la representación de la figura masculina ha estado presente a lo largo de los siglos en el arte, el cuestionamiento sobre la construcción de lo masculino es un fenómeno que se evidencia junto con las reflexiones sociológicas y filosóficas que fundamentan el feminismo y los estudios de masculinidades en las últimas décadas del siglo anterior. Por ello, aunque la finalidad de este artículo no es hacer una revisión histórica, sí es pertinente mencionar algunos antecedentes importantes de este proyecto.

Ante las corrientes creativas que ponen en entredicho las construcciones del género, desde el cuerpo femenino reivindicado en su reapropiación de las artistas mujeres que hemos mencionado, surge también la reflexión crítica respecto a la estructura binaria que da lugar a que se incorporen y adquieran potencia en el arte las miradas de las minorías o disidencias sexuales o los colectivos LGTBIQ+, alcanzando en los ańos 80 mayor fuerza con los estudios sociológicos y antropológicos acerca de las masculinidades alternas.

Elena Sachetti, en su artículo «Andreia y sus contrarios. Masculinidades plurales a través del arte» (2012), hace un análisis de las representaciones de las masculinidades en el arte contemporáneo, mencionando exposiciones y artistas que han abordado este tema. Entre ellos destacan nombres como Alex Frances, Miguel Bennloch, Antonio Sosa y Jesús Martínez Oliva. Este último, además, destaca como investigador acerca de las masculinidades en el arte, siendo autor del libro titulado El desaliento del guerrero. Representaciones de la masculinidad en las décadas de los 80 y 90, publicado en 2005 .

Otro antecedente importante de mencionar es la exposición «Héroes Caídos», desarrollada en Espai d'art contemporani de Castelló en 2002 y que Fabricio Forastelli releva y analiza en el número 6 en la revista Dossiers feministes, dedicado a las masculinidades, editado ese mismo año. En el texto se pone de relieve la discusión teórica fundamentada por autores como Weeks y Halberstam (2002), que dan origen a la muestra, que incluye fotografías de Del LaGrace Volcano, John Coplans, Mark Morrisroe y Juan Pablo Ballester; esculturas de Paul McCarthy; pinturas de Gilbert and George; vídeos de Peter Land y exhibiciones de Javier Codesal (cine) y Jesús Martínez Oliva (Internet), que dan cuenta de las reflexiones que ponen en cuestión las visiones de la masculinidad hegemónica, el binarismo, la estética queer, con la finalidad de abordar la problemática acerca de la deconstrucción de las estructuras imperantes para la identificación en cuanto a género (Forastelli 2002).

\section{SÍMBOLOS DE IDENTIDAD, OBJETOS DE MASCULINIDAD}

Al hacer un análisis respecto a los estudios de género y en particular a los planteamientos de Judith Butler y la teoría queer, el carácter performativo de la identidad de género es fundamental, lo que implica que se articula a partir de los actos 
del cuerpo, cuyos significados están enmarcados y configurados en las relaciones significativas de este y su contexto, lo que queda sintetizado por la misma Judith Butler en las siguientes palabras: «Los distintos actos de género producen el concepto de género, y sin esos actos no habría ningún género» (2007, p. 272).

No obtente, no podemos pensar que solo se pueda actuar como mujer o como hombre y desconocer que las construcciones culturales de género se manifiestan también en los objetos que complementan y se originan en ese actuar. Todo objeto es portador de un significado que en primera instancia es su función práctica, pero condensará más allá de aquella los significados propios del acto de su génesis y de su uso y, por lo tanto, hablará de su origen humano, social y cultural. Entendiendo la cultura como "la manera en que se producen mundos significativos» (Friedman 2001, p. 25). En los objetos, «nuestra percepción reconoce el reflejo de las creencias compartidas dentro de alguna de las comunidades a las que pertenecemos, y también de nuestra biografía» (Martín Juez 2002, p. 14).

Lo anterior significa que a partir de objetos podemos elaborar discurso y, así, podemos trabajar desde el lenguaje visual para deconstruir y resignificar esos elementos. En ese sentido, la ciudad, como producto cultural, condensa multitud de significados que se articulan en densas estructuras simbólicas. Como lo señalan autores desde las teorías del construccionismo social (Berger y Luckman), desde el interaccionismo simbólico (Georg Simmel, George H. Mead, Herbert Blummer, Erwing Goffman) y desde la psicología social (Moscovici, Castorina, Lloyd y Duveen), la ciudad no es solo el escenario en que se desarrolla la vida de los individuos como un mero entorno materialmente construido, sino como una construcción que más allá de una dimensión física posee una dimensión simbólica que establece una serie de categorías que definen a sus habitantes. La ciudad se entiende entonces como el producto de

... la interacción social donde los sujetos construyen su identidad, esto es, manifiestan su habitus o cultura incorporada a través de prácticas -formas de comportamiento y actuación - concretas. Y es en esa interacción social, también, donde los actores construyen y comparten las representaciones sociales acerca de sí mismos, de los otros y el entorno que los rodea (Rizo 2005, p. 14).

En el contexto de la ciudad posmoderna, la articulación de una identidad y el desarrollo de una personalidad resulta un constante conflicto interno de decisión a partir de infinidad de opciones, siempre relativizadas. Stuart Hall (1996) reflexiona respecto a ello, entendiendo que en los tiempos de la modernidad tardía las identidades se ven enfrentadas a procesos de fragmentación y fractura y que, por lo tanto, lejos de constituir una unicidad, se construyen de diversas formas a partir de prácticas y discursos a veces incluso contradictorios.

Uso «identidad» para referirme al punto de encuentro, el punto de sutura entre, por un lado, los discursos y prácticas que buscan «interpelarnos», hablarnos o ponernos en nuestro lugar como sujetos sociales de discursos particulares y, por otro, los procesos que producen subjetividades, que nos construyen como sujetos susceptibles de «decirse» (1996, p. 20). 
Dicho lo anterior, podemos entender que en esa densa estructura de significados con que los individuos interactúan en la ciudad, se encuentran también aquellas construcciones sociales que definen y configuran los procesos identitarios referidos al género. De esos conceptos que surgen desde distintas perspectivas de las ciencias sociales, se deriva un imaginario que engrosará el «abecedario» o "vocabulario" visual que permitirá elaborar metáforas y discursos acerca de la temática del género, posicionándose en una perspectiva deconstructiva. Así, la fractura, la fragmentación y la sutura son recursos conceptuales que remiten precisamente a deconstrucción.

Pierre Bourdieu (2010), en La dominación masculina, se refiere a la construcción social de los cuerpos, derivada de la asignación de significados culturales y sociales, a la anatomía de los seres humanos: «El mundo social construye el cuerpo como realidad sexuada y como depositario de principios de visión y división sexuantes. El programa social de percepción incorporado se aplica así a todas las cosas del mundo...» (p. 22). A partir de ello, el falo ocupa un lugar fundamental en la jerarquización de la sociedad. Como señala el sociólogo francés, «el acto sexual en sí mismo está pensado en función del principio de la primacía de la masculinidad. La posición entre los sexos se inscribe en la serie de oposiciones mítico/rituales: alto/ bajo, arriba/abajo, seco/húmedo, cálido/frío, activo/pasivo, móvil/inmóvil» (p. 31).

El falo, la proyección del cuerpo del varón hacia el frente que en el acto sexual penetra o invade el cuerpo de la mujer en un acto de fecundación y, al mismo tiempo, como un acto de posesión, se convierte en el símbolo y la idealización de la anatomía. Judith Butler, en Cuerpos que importan, en relación con lo planteado por Lacan y desde el psicoanálisis, señala:

... ese órgano imbuido narcisísticamente se eleva luego a la condición de principio estructurante que forma y da acceso a todos los objetos cognoscibles. En primer lugar, esta versión de la génesis de las relaciones epistemológicas implica que todos los objetos cognoscibles tendrán un carácter antropomórfico y androcéntrico. En segundo lugar, este carácter androcéntrico será fálico (2002, p. 124).

Sobre esa base, el psicoanálisis ha vinculado el falo con la idea del exterior, con el carácter público del ejercicio de la masculinidad y de la configuración de las relaciones de significado, lo que implica una relación con los otros desde la competitividad por el posicionamiento en relaciones de poder.

Duch (2002), por su parte, señala que la ciudad es una estructura de acogida, pues es el contexto social en el que el ser humano se relaciona con los demás miembros y con las pautas culturales que lo determinan. La ciudad, entonces, se convierte en un espacio al cual también el habitante se adapta en relación con quienes la habitan, más allá de los elementos físicos. Sin embargo, se puede establecer una relación metafórica de la imagen de la ciudad, en su carácter concreto y corporal, a través de su materialidad y los objetos que distinguen al hombre como un habitante de la urbe, y el acto de construirse ante la vida a partir de la historicidad de la existencia, a partir de las experiencias, el recuerdo y los afectos, enmarcados dentro de un rol, comportamiento y hábito determinado por las construcciones culturales que la ciudad refleja. 
En el tránsito por la ciudad se hacen concretas esas estructuras, en la publicidad callejera, en los locales comerciales que llaman al consumo, en los muros, en los habitáculos, en la vestimenta y el comportamiento de quienes habitan y transitan por «la jungla de cemento». Dentro de un contexto social que presenta como validación la persecución de representaciones sociales, es decir, el conjunto de valores e ideas que generan prácticas reguladas, que fomentan la competitividad, el individualismo y el consumo, los elementos de la ciudad, como el cemento y el metal, se articulan como significantes de esos contenidos y se suman a los recursos del lenguaje visual para la construcción de discursos referentes a las problemáticas de género (Lloyd y Duven 2003).

Sobre la relación de aquellos signos presentes en lo urbano podemos elaborar objetos visuales, que se conciben como obra de creación artística, que en su conjugación dialéctica se presentan como simbolismo de los conceptos de identidad y personalidad como construcción a partir de la experiencia. Entendido que, como hemos dicho antes, la identidad «no es algo esencial, fijado a priori, sino que se va construyendo a través del trayecto histórico del ser humano desde el nacimiento hasta la muerte» (Duch 2002, p. 14), la relación simbólica se da al hablar de lo humano a partir de los elementos de la ciudad que remiten a la idea de construcción, como la materialidad y también la vestimenta formal, lo que configura el relato visual en el que intervienen las figuras retóricas como parte de la elaboración discursiva de la imagen y que iremos explicando en próximas líneas.

Llegados a este punto, se hace necesario tener referencias visuales, puesto que a continuación aludiremos a la interacción de elementos visuales que se elaboran a partir del análisis de los conceptos que hemos ido desarrollando en estas líneas. Presentaremos cuatro cuadros pertenecientes a la serie «El Género Anudado. Símbolos de masculinidades", que consisten en corbatas de $110 \mathrm{~cm}$. de altura confeccionadas en tela y dispuestas sobre un lienzo, configurando un cuadro volumétrico que es intervenido pictóricamente con diferentes técnicas y materiales, como acrílico, óleo, metal, cemento y arena (ver figs. 1, 2, 3, 4).

El acto de vestirse es el reflejo de la construcción de la personalidad, entendida como lo señala Engler (2003), como la imagen pública que proyecta cada individuo, aquello de la identidad que se muestra y es percibida por el otro y que permite insertarse en un medio social. En ese sentido, la vestimenta nos remite a aquel concepto de la masculinidad relativa a su carácter público. Como lo señala Gilmore, «ser un hombre es una modalidad pragmática y activa, una participación en el escenario público de las acciones y actos y de logros concretos y visibles» (1994, p. 46).

Dentro de las prendas de vestir, la corbata es un elemento que es particularmente sugerente. Este objeto es un elemento propio del hombre y su uso se circunscribe específicamente a la ciudad. Es interesante puesto que en el amplio espectro de los objetos cotidianos no existe otro cuya función sea eminentemente simbólica. Desde la antropología, los análisis estructuralistas y desde la semiótica (Baudrillard, J., Moles A., Eco, U., Costa, J.) se han analizado los significados de los objetos en cuanto productos culturales mediatizadores, y a partir de ello podemos entender los significados de los objetos en un nivel denotativo funcional, y en niveles más complejizados, en su relación con el usuario, como parte de un fenómeno de rela- 


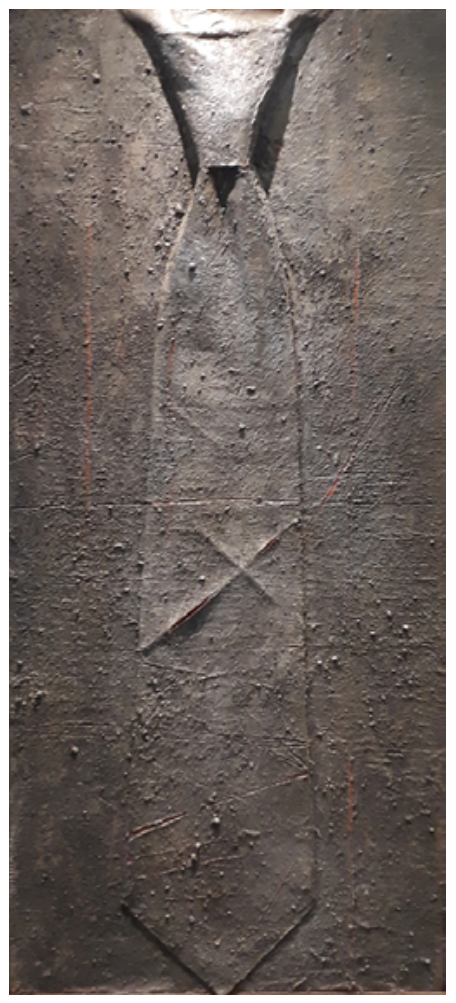

Fig.1. Muro. Serie «El Género Anudado. Símbolos de masculinidades». Acrílico, arena y cemento sobre objeto sobre lienzo. $110 \times 50 \mathrm{~cm}$.

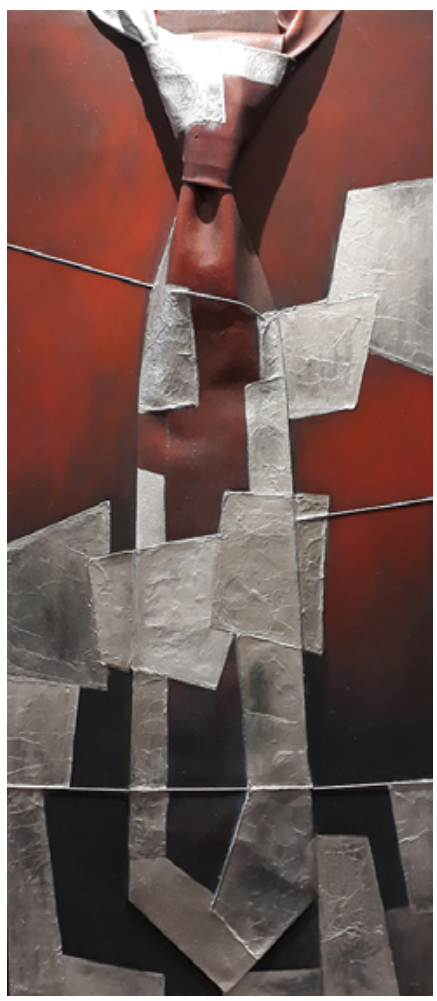

Fig. 2. Rojo. Serie «El Género Anudado. Símbolos de masculinidades». Acrílico, aluminio, alambre sobre objeto y lienzo. 110x50 cm.

ciones significativas, adquiriendo connotaciones simbólicas. Ahora bien, el caso de la corbata tiene la particularidad de que, no solo su función simbólica es determinante en su definición, sino que esta es exclusiva puesto que no posee una función práctica o utilidad.

Utilizando la semiótica como mecanismo de análisis, la corbata posee, en un nivel icónico, una forma alargada que se ensancha levemente en uno de sus extremos, se concibe de manera vertical por su posición de uso y su mecanismo de utilización es al modo de soga que se anuda para rodear el cuello. Además de ello, la forma alargada alude, a modo de reflejo o proyección exterior, al falo, que, como ya hemos dicho, en términos lacanianos es el «significante privilegiado». Respecto a lo que la corbata señala o indica, podemos decir que remite a un contexto público, se usa particularmente en situaciones de formalidad y solemnidad como es el trabajo, como, por ejemplo, ejecutivos de empresas, instituciones públicas, políticas y judiciales, todas ellas áreas relacionadas con la 


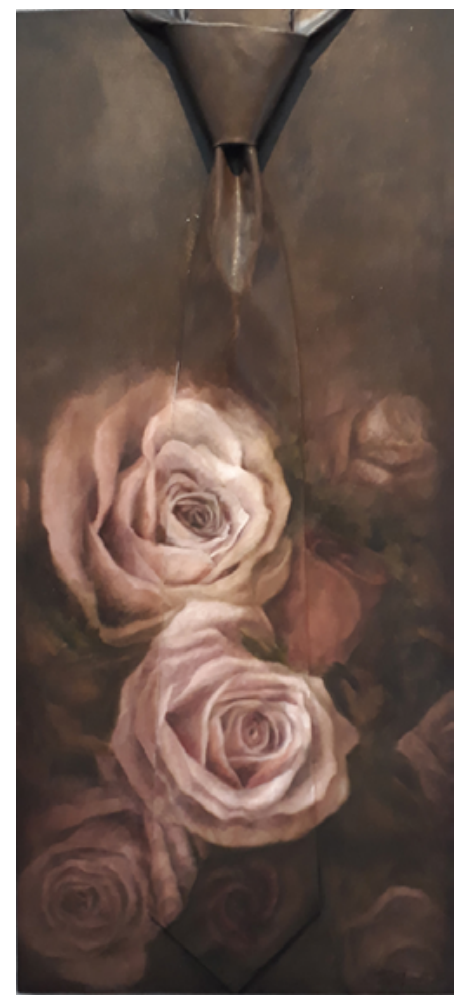

Fig. 3. Rosas. Serie «El Género Anudado. Símbolos de masculinidades».

Óleo sobre objeto y lienzo. $110 \times 50 \mathrm{~cm}$.

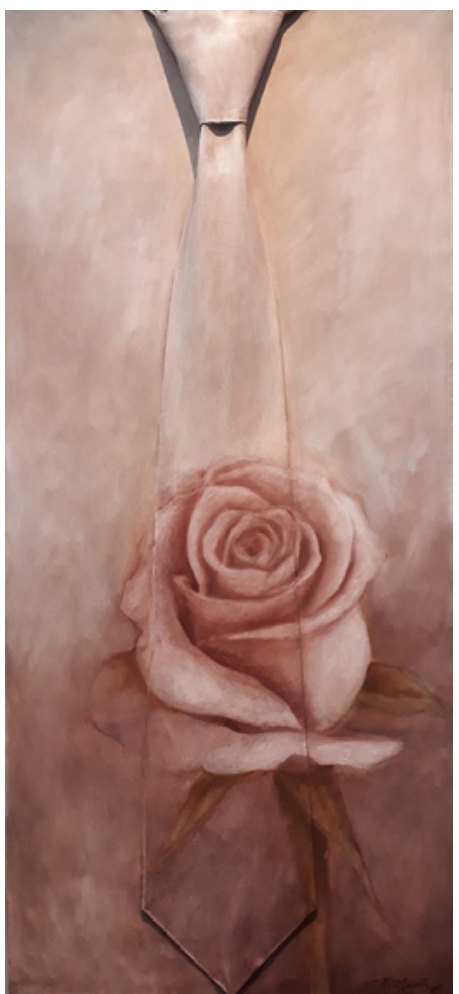

Fig. 4. Rosa. Serie «El Género Anudado. Símbolos de masculinidades». Óleo sobre objeto y lienzo. $110 \times 50 \mathrm{~cm}$.

racionalidad, la intelectualidad y la mente, culturalmente asociado a lo masculino en las estructuras binarias de las construcciones sociales de género. Como señala Butler: "Las asociaciones culturales de la mente con la masculinidad y del cuerpo con la feminidad están bien documentadas en el campo de la filosofía y el feminismo» (2007, p. 64).

Así mismo, en su carácter de objeto simbólico, la corbata remite a la solemnidad, puesto que es utilizada en situaciones ritualizadas. En el rito, la corbata como implemento corporal se relaciona en el sistema de significación que en esos contextos se articulan de manera performativa. Así, la corbata es fundamental en la actuación ceremonial de matrimonio, en una titulación académica, en los discursos y debates políticos, entre otras situaciones de relevancia pública. En definitiva, la corbata se convierte en un símbolo de jerarquía y poder, pues trasmite seriedad y control, es decir, proyecta las categorías propias de la masculinidad hegemónica. 
Por otra parte, los significados a los que hemos hecho mención son los que el objeto corbata tiene en su contexto normal en el que tiene cabida. Cuando desarrollamos, a partir de ellos, procesos de resignificación o de resemantización a través del lenguaje visual, que se concretizan en la elaboración de objetos de creación artística, se producen metáforas que remitirán a nuevos significados indirectos.

Ya al pintar la corbata, en el acto mismo de untar pintura sobre ella, se está desarrollando un acto de significación que cuestiona y pone en interacción los significados del objeto con el hecho de ser cubierta, de ser tapada, o de ser soporte de una imagen. Al entrar en ese proceso, el campo semántico se reorienta, así la corbata se puede entender en su relación con lo humano y el vínculo con lo emocional, se puede interpretar como una soga que el hombre se ajusta al cuello, parte central del funcionamiento del cuerpo y de la vida, y además de ceñirse a él, se anuda sobre la garganta, lo que remite a la forma común de referirse la contención emocional.

Se articula de esa manera parte del discurso visual que cuestiona la estructura heteronormativa y androcéntrica, que consolida la masculinidad hegemónica como una soga de opresión también para los hombres que cargan con ella.

En términos más concretos, la adquisición de la masculinidad hegemónica (y la mayor parte de las subordinadas) es un proceso a través del cual los hombres llegan a suprimir toda una gama de emociones, necesidades y posibilidades, tales como el placer de cuidar de otros, la receptividad, la empatía y la compasión, experimentadas como inconsistentes con el poder masculino (Kaufman 1995, p. 8).

El autor citado alude desde otra perspectiva al efecto de la posición de dominio del hombre en la estructura social, la perspectiva del dolor. Para Kaufman, ser hombre no es una tarea fácil y, aunque el goce de la posición privilegiada en el binomio hombre/mujer es un beneficio, este no es gratis e implica un sacrificio para algunos hombres. Demostrar constantemente en el ámbito público la masculinidad es, desde muy temprana edad, una competencia en la cual no es posible ceder. Bourdieu lo plantea en las siguientes palabras: «El privilegio masculino no deja de ser una trampa y encuentra su contrapartida en la tensión y la contención permanentes, a veces llevadas al absurdo, que impone en cada hombre el deber de afirmar en cualquier circunstancia su virilidad» (2010, p. 68).

Desde la retórica visual, lo anterior se articula visualmente a través de la hipérbole, es decir, la exageración del tamaño de la corbata, lo que permite además descontextualizarla y pone el acento en significados específicos relativos a la idea de las estructuras que se imponen como mecanismos de regulación y dominación.

Así mismo, por ejemplo, de los conceptos propios de lo urbano, además de la idea del habitante de la ciudad que se diluye en el colectivo, impersonalizándose paradójicamente en su individualismo, establecemos el vínculo con la serialización de la arquitectura de las ciudades industriales modernas, como símbolo de aquella construcción social de la masculinidad, relacionada con el orden, la simetría, la formalidad y la contención. 
Ahora bien, además de lo anterior, el lenguaje pictórico nos permite incorporar elementos que se vinculan con el contrapunto, el lado emocional y vulnerable a través de signos que trasmiten la idea de construcción, en sentido arquitectónico y en sentido psicológico, convergiendo en el significado de fortalecimiento, lo que es propio de lo socialmente masculino. El gesto pictórico más matérico se incorpora entonces para aludir a la idea de construcción que protege, como un muro que se hace necesario para ocultar y solventar la vulnerabilidad. Por otra parte, a través de la pintura más diluida y la pincelada modelada, se incorporan signos que se relacionan con características asociadas a la feminidad, estableciendo de esa manera el discurso visual deconstructivo, o abordando las diversas formas de masculinidades que existen en la sociedad. A partir de la representación de la rosa, la flor como símil del órgano reproductor, delicada, suave y rosada, la feminidad subvierte el cetro simbólico de la corbata.

Algunos hombres tendrán la suerte de amoldarse sin dificultad a esa horma que define sus contornos masculinos, algunos la asumirán sin inconveniente, incluso se sentirán cómodos y serán precisamente quienes más defiendan el privilegio que les ha tocado por la gracia de nacer anatómicamente varones. La masculinidad hegemónica plantea un hombre indolente, al que le es complicado generar la capacidad de sentir el dolor de otros y empatizar, puesto que además no le es necesario, como lo describe Kaufman: «La alienación de los hombres es la ignorancia de nuestras emociones, sentimientos, necesidades y de nuestro potencial para relacionarnos con el ser humano y cuidarlo» (1995, p. 10).

Cuando vivimos en una sociedad determinada por la competitividad, el capitalismo, el mercado y la cultura de la incertidumbre, la masculinidad hegemónica resulta totalmente coherente. Ese escenario público, que es la ciudad, se muestra como ese ambiente hostil, violento y feroz, donde el riesgo es cotidiano, y es configurado por los hombres, para que los hombres se enfrenten unos a otros por el poder. Salir de casa a ese lugar lleno de rivales es un riesgo, porque la persona que habita la ciudad carece de interés por los demás, las relaciones se reducen al plano absolutamente racional y los demás son considerados como medios para la obtención de fines personales (Ulf 1986).

Frente a los otros es necesario construirse una identidad fuerte, una personalidad, una coraza protectora que a la vez oculta y reprime la emocionalidad latente, el dolor y las huellas de la sensibilidad. Como señala Kaufman: «Esta forma de opacar el sentido del dolor es otra manera de decirles a los hombres que deben aprender a llevar puesta una armadura, es decir, que debemos mantener una barrera emocional frente a los que nos rodean para poder seguir luchando y ganando» $(1995$, p. 9).

Fragmentación, fractura, sutura, corbata, construcción, cemento, fragilidad, naturaleza, muro, público, exterior, falo, armadura, flor, rosa... Han surgido de estas líneas una serie de palabras, de significantes que podemos tomar como recursos visuales que se conjugan en la reflexión propia del proceso creativo. Emergen producto de un análisis de una serie de categorías derivadas de conceptos teóricoconceptuales que, luego, en un proceso de creación artística, se articula a modo de "trabajo de campo" en que se elabora un trabajo reflexivo que apunta a construir un discurso desde la visualidad. Ese proceso de transfiguración, desde el concepto 
o la idea a la visualidad, es lo que constituye la investigación que apunta a la creación. En este caso, la sociología, la psicología social, la antropología sirven para la comprensión de los conceptos, y para nutrir el proceso analítico y reflexivo de la creación artística, que en el contexto del arte contemporáneo no puede dejar de ser discursivo y, por lo tanto, político.

\section{CONCLUSIÓN}

Para concluir, cuando hablamos de género y lo definimos como las construcciones sociales, no hablamos solamente de mujeres. Hablamos de seres humanos, todos ellos configurados por esa estructura que delimita y define un modelo de ser sobre la base de las diferencias sexuales. Pero esas estructuras, además de delimitarnos, establecen una relación de poder y jerarquía que ha puesto a la mujer y lo femenino en posición de subordinación ante el hombre y lo que entendemos como masculino. No obstante, es preciso plantear que, más que la mujer misma, lo que ha quedado en posición de inferioridad ha sido todo aquello que no responde a una construcción de un ser humano ideal, que se sitúa en la cúspide de la sociedad (en cuanto a género): el hombre heterosexual, que posee además una serie de atributos ficticios que se derivan de la negación de lo femenino. La masculinidad hegemónica se entenderá como la negación de "lo humano», es decir, la fuerza, la insensibilidad, la temeridad, la violencia y la agresividad, el repudio de todo aquello que nos hace conectar con el otro, comprenderlo y empatizar.

A partir del análisis que hemos hecho de las teorías de género, tanto de los estudios feministas y luego sobre los estudios de masculinidad, y viendo que las construcciones de género nos llevan a entender el carácter opresor de esas estructuras, hemos establecido las relaciones con el imaginario que de ello se desprenden. Encontramos en la ciudad, la manifestación material de esas construcciones sociales, un conjunto de signos que permiten, desde el lenguaje de las técnicas mixtas de la pintura y las artes visuales, elaborar objetos que pretenden poner en cuestionamiento la rigidez de la estructura de la masculinidad. Por lo tanto, vale decir que esta investgación creativa parte desde una postura crítica respecto a la estructura binaria impuesta por el patriarcado, que trabaja a partir de los signos y símbolos que esta sostiene, pero los rearticula analíticamente a partir de la reflexión artística para subvertirlos y resignificarlos para activar su cuestionamiento.

A partir de estas corbatas descontextualizadas y resignificadas, el falo se ve desconfigurado, interpelado por otras formas de «vestir», de proyectarse. Formas que hacen alusión a la dilución de los márgenes, a las nuevas formas de identidad de los hombres en la sociedad actual, a las diversas formas de vivir y relacionarse con el entorno y con los otros individuos de la sociedad, desde la empatía, la igualdad y no desde el poder, la opresión y la violencia. 


\section{BIBLIOGRAFÍA}

Baudrillard, J. (1985). «El Éxtasis de la comunicación», en Foster H. (ed.) La posmodernidad, Barcelona: Kairós, pp. 187-235.

Baudrillard, J. (1990). El sistema de los objetos (11. ${ }^{a}$ ed.). México D.F.: Siglo Veintiuno Editores.

Beauvoir, S. (2005). El segundo sexo. Madrid: Ediciones Cátedra.

Bourdieu, P. (2010). La dominación masculina. Barcelona: Anagrama.

Butler, J. (2007). El género en disputa. El feminismo y la subversión de la identidad. Barcelona: Paidós.

Chodorov, N. (1984). El ejercicio de la maternidad. Barcelona: Gedisa.

Derrida, J. (1996). «Remarks on Deconstruction and Pragmatism», en Mouffe, C. (ed.) Deconstruction and pragmatism, Londres: Routledge, pp. 79-90.

Duch, L. (2002). Antropología de la vida cotidiana. Madrid: Editorial Trotta.

Forastelli, F. (2002). "Masculinidad, homosexualidad y exclusión. Sobre la muestra "Héroes caídos” del Espai d'Art Contemporani de Castelló». Dossiers feministes, n. ${ }^{\circ}$ 6, pp. 111-126.

Friedman, J. (2001). Identidad cultural y proceso global. Buenos Aires: Amorrortu Editores.

Gilmore, D. (1994). Hacerse hombre. Concepciones culturales de la masculinidad. Barcelona: Paidós.

Guash, O. (2008). «Los varones en perspectiva de género». Asparkía, n. ${ }^{\circ}$ 19, pp. 29-38.

Hall, S. (1996). “¿Quién necesita “identidad”?», en Hall, S., Du Gay (eds.) Cuestiones de identidad cultural, Buenos Aires: Amorrortu Editores, pp. 13-39.

Harvey, D. (1990). La condición de la Posmodernidad. Investigación sobre los orígenes del cambio cultural. Buenos Aires: Amorrortu Editores.

Jociles, M.I. (2001). «El estudio de las masculinidades. Panorámica General». Gazeta de Antropología, n. ${ }^{\circ} 17$, artículo 27.

Jones, A. (2010). "Generando problemas. Las artistas feministas ponen en escena el sexo femenino». Revista Youkali, n. ${ }^{\circ} 11$, pp. 46-54.

Kaufman, M. (1995). Los hombres, el feminismo, y las experiencias contradictorias del poder entre los hombres. URL: http://www.michael-kaufman.me/wp-content/uploads/2008/12/loshombres-el-feminismo-y-las-experiences-contradictorias-del-poder-entre-los-hombres.pdf; consulta hecha el día 16/11/2020.

Kimmel, M. (1997). «Homofobia, temor, vergüenza y silencio en la identidad masculina», en Valdes, T. y Olavarría, J. (eds.) Masculinidadles: poder y crisis, Santiago de Chile: ISIS-FLACSO, Ediciones de las Mujeres, cap. 3, n. ${ }^{\circ}$ 24, pp. 49-62.

Lacan, J. (1958). «La significación del falo». Escritos II. Buenos Aires: Siglo Veintiuno Editores, pp. 665-675.

Lloyd, B. y Duveen, G. (2003). «Un análisis semiótico de las representaciones sociales de género» en Castorina, J.A. (comp.) Representaciones sociales. Problemas teóricos y conocimientos infantiles, Barcelona: Gedisa, pp. 38-52.

Martín Juez, F. (2002). Contribuciones para una antropología del diseño. Barcelona: Gedisa.

Martínez Oliva, J. (2005). El desaliento del Guerrero: representaciones de la masculinidad en el arte de los 80 y 90. Murcia: CedeAC. 
Rizo, M. (otoño 2006). "Conceptos para pensar lo urbano: el abordaje de la ciudad desde la identidad, el habitus y las representaciones sociales». Bifurcaciones, n. ${ }^{\circ}$ 6. URL: <http:// www.bifurcaciones.cl/006/Rizo.htm>. ISSN 0718-1132; consulta hecha el día 09/01/2017.

SAChetti, E. (2012). «Andreia y sus contrarios. Masculinidades plurales a través del arte». AIBR, Revista de Antropología Iberoamericana, vol. 7, n. ${ }^{\circ}$ 3, pp. 361-394.

Sсотт, J. (1986). «El género: una categoría útil para el análisis histórico», en Lamas, M. (comp.) El género: la construcción cultural de la diferencia sexual, México: PUEG, pp. 256-302.

Ulf, H. (1986). Exploración de la ciudad. Hacia una antropología urbana. Mexico: Fondo de Cultura Económica.

Wittig, M. (2006). El pensamiento heterosexual y otros ensayos. Madrid: Egales. 